\title{
Approach to the autistic spectrum disorder
}

DOI: $10.46932 / \operatorname{sfjdv2n2-052~}$

Received in: january 1st, 2020

Accepted in: March 30th, 2020

\author{
Cristina Maria Belmonte Pérez \\ Graduada Educación Primaria. Especialista en Pedagogía Terapéutica. \\ Instituição: RG Formación \\ Calle Rosalía de Castro, 44, 30107 Murcia \\ Isabel Albaladejo Martinez \\ Graduada Educación Primaria. Especialista en Pedagogía Terapéutica. \\ Instituição: RG Formación \\ Calle Rosalía de Castro, 44, 30107 Murcia \\ Nerea Liza Clares \\ Graduada Educación Primaria. Especialista en Pedagogía Terapéutica. \\ Instituição: RG Formación \\ Calle Rosalía de Castro, 44, 30107 Murcia \\ Jose María Rabal Alonso \\ Profesor ISEN Centro Universitario \\ Instituição: ISEN \\ Calle Menéndez y Pelayo, 8, 30204 Cartagena, Murcia \\ E-mail: josemaria.rabal@um.es
}

\begin{abstract}
The objective of the work that we are going to present below is to choose a type of disability, in our case the Autism Spectrum Disorder, on which we will work with the intention of developing an educational project in which the students are given a response, having take into account the individual characteristics of each of them, as well as the context in which they are found. We decided to choose this disability because the four members of the group have treaty, at some point in our life, with people who have Autism Spectrum Disorder, whether they are children or adults. Therefore, it seemed a good idea to work on a topic that we have had the opportunity toapproachpersonally one way or another. However, this does not mean that, by having had the opportunity to meet and interact with people with this syndrome, we have known how to act with and towards them. It is for this reason that we would like to be able to know their characteristics and the needs they need to be able to successfully achieve in our future what we do notwe knew how to doin the past, that is, to contribute to a good development of the student body and to cooperate to achieve their integration into society.
\end{abstract}

Keywords: inclusion, special education, attention to diversity, ASD, asperger's, autism.

\section{INTRODUCTION AND JUSTIFICATION}

In the first place, it is necessary to research about Autism Spectrum Disorder. This is defined as a severe developmental disorder that entails a neurological alteration. Although it often tends to be confused 
with Autism, since it has similar characteristics, these differ in the degree of affectation, being the Autism Spectrum Disorder less.

People with this disability do not have apparent characteristic features, but they tend to have certain common characteristics: difficulties in social interaction, communication and flexibility of thought.

- Difficulties in social interaction. They tend to be socially awkward people, that is, they may issue the wrong message by mistake, they may not understand the ironies or according to what kind of gestures, they are uncomfortable when the person they interact with gets too close, they do not understand emotions or intentions of the other person, etc. In addition, they are usually innocent, sincere, credulous and have no malice. In short, although they try to be sociable, they do not enjoy social contact, although it is true that these children tend to connect better with adults than with their peers.

- Communication. Although they acquire good grammatical and vocabulary development, they have difficulties in communication processes because they have problems to carry and maintain the rhythm of the conversation. They are usually monotonous, both in terms of conversation and intonation, and do not use facial expressions or gestures in the composition of their speech. Also, they often have trouble understanding jokes or metaphors.

- Imagination and inflexibility of thought. People with Asperger's tend to prefer mechanical and systematic activities or games because they have difficulty understanding the implicit rules of other types of games. In addition, they are very routine and repetitive people, which causes a certain aversion to changes. In contrast, they usually have specific interests, that is, they are attracted to a particular topic and frequently investigate it.

\section{CONTEXTUALIZATION}

\subsection{SCHOOL CONTEXT}

We are located in a publicly owned center located in the district of Los Garres (Murcia), in which students of Infant and Primary Education are educated.

As we have mentioned previously, the center is located in Los Garres, a Murcian district located to the Southeast of the municipal term, under the shelter of the Sierra de la Cresta del Gallo, at a distance of about $3.5 \mathrm{~km}$ from the capital. Because it is located in a residential and not central area, it is a quiet place away from noise. This limits to the North with Los Dolores; to the East with San José de la Vega and Beniaján; to the West with San Benito; and, to the South with Algezares.

The Antonio Díaz Public School is a center that has an ordinary schooling modality that is distributed in four buildings located in different sectors of the town: 
- Pavilion A. In it the first section of Primary Education is taught. In addition, in this building we also find the open classroom that this center has, which at this moment is made up of 7 students who require Specific Needs for Educational Support.

- Pavilion B, where the students of the second section of Primary Education are located.

- The Early Childhood Education pavilion, where children from 3 to 5 years old are.

- The San José pavilion, a different building located in the San José de la Montaña neighborhood, a space where boys and girls from different grades are in the same classrooms due to the small number of students.

Our classroom corresponds to the 3rd A class, belonging to the first section of Primary Education. It is a space that has an approximate capacity to accommodate about 25 students. This year, our class is made up of 12 girls and 8 boys of different nationalities (Spanish, South American and African). Among the different students, we find a small numberwhose learning pace is lower than the rest and require greater attention. Three of them attended reinforcement and support classes in the subjects of Spanish Language and Literature, and Mathematics, because two of them present cases of Dyslexia, and the third, being a student who comes from another country with a language and a different culture, they need to develop their communication skills since they understand the language, but they need to improve their oral and written expression in order to facilitate their integration.In addition, we have a student with Autism Spectrum Disorder who needs specific needs for educational support. This student has had various difficulties throughout her stage in Primary Education when interacting with her peers, due to not having managed to understand or express her own emotions and, therefore, is not able to empathize with the rest of the boys and girls. One of the various consequences of this is the lack of skills to face the different situations of their day to day.

Taking into account the diversity of our students and the difficulties detected when observing the characteristics of each one of them, we can say that, in general, the learning pace is heterogeneous. Therefore, before beginning our teaching-learning process on curricular content in this new course, we consider that it is convenient to work, first of all, on transversal content, specifically, starting from emotions in order to achieve group-class cohesion. and self-knowledge and knowledge of others.

At all times, as teachers, we want all students to be integrated despite their difficulties in the tasks, in the language or in their adaptation to comply with the different standards. Therefore, the different relationships existing in the classroom (teacher-teacher, teacher-student, student-student) are based on respect and collaboration.

Space distribution 
The size of the classroom is quite large and therefore there are no problems getting from one place to another. In addition, we have a series of corners: reading, games and computing, where students can develop different skills. This classroom is located on the first floor of pavilion A. In front of it was the Music class and, between them, there is a room where a large amount of materials and resources are kept, such as paintings, cardboard, audiovisual materials, etc. The way to access the classroom is through some stairs. From this fact a problem arises because, if a child or teacher needed to go to class on crutches or a wheelchair, it would be almost impossible for them to access it.

Regarding the distribution of spatial resources in the classroom, we must point out that it is medium in size, and that a large amount of natural light falls on it through three large windows. The ventilation conditions are also very good since, in addition to the windows, the class had three other small windows on the other side of the classroom where the air constantly entered. Thanks to these conditions, which occur in both winter and summer, the temperature is very pleasant, which provides a suitable climate for the teaching and learning process to develop. With regard to sound, being located in front of the Music class, sometimes it is necessary to close the door since the sound that comes from it can get the students out of focus.

\section{$\underline{\text { Human resource distribution }}$}

The spatial organization of the students within the classroom is as follows: they are grouped into four integrated teams, each of them by five students. The teacher's table is located in the center of the classroom, which facilitates the control of the classroom and the students. In addition to the tutor or teacher who is teaching the class at that time, it is also possible to find other teachers, such as the support teacher. Distribution of material resources

The material resources that the classroom has are the following: a traditional blackboard and a digital one, a projector, several shelves where they keep the materials used in class (dictionaries, books, notebooks, games, etc.). In addition, of all the aforementioned aspects, the classroom has various murals, maps and works carried out by the students.

As we have commented previously, the class has three corners where different activities are carried out:

- The reading corner: here are the books that students read in class and at home. In addition, there are also 20 dictionaries that students use when needed.

- The logical-mathematical and technological game corner: this space is intended for students to put their logic and mathematical ability into practice through games such as puzzles, constructions, creation of machines, etc. 
- The computer corner. In it is the computer in which the students look for information and carry out work.

\subsection{SOCIAL CONTEXT}

If we take a look around the center of the town of Los Garres, we can find several blocks of houses with a medium socioeconomic level, as well as various parks where, in general, students meet during nonschool hours. to culture, very close to the center we find the meeting place of the Peña Huertana de Los Garres, called "Peña Huertana El Caliche" and, next to that place, we see a stage where they perform several of their performances. Likewise, there is also a gutter with the Los Garres Musical Association and the "El Rayo" Athletics Club. This can be a plus for children to become interested in the culture of their town. In addition, it also has healthcare infrastructures (library, city hall, Cultural Center, Women's Center, soccer field, weekly street market, etc.

\subsection{FAMILY CONTEXT}

As we know, it is essential to take into account Valeria's family context in order to understand many of her behaviors, since the family relationship influences the development of the social dimension, communication, interaction, personal growth, etc.

Until four years ago, Valeria's family consisted of her father, mother, and herself. The attention to the girl was constant, she received many positive reinforcements from her parents and they had a very good family relationship, as well as a high economic and sociocultural level. This offered the girl security and, despite her difficulties in the social sphere, she used to defend herself and be well integrated with her peers. However, this great progress came to a halt when problems began to exist between their parents, leading to divorce and, two years later, the birth of a brother by their father and his new partner.

For Valeria, this change was not easy, which she has not yet accepted, and this has had a negative influence on the social area. However, the relationship between her parents is still quite good and, although she lives with her mother, her father visits her constantly. In addition, every two weeks Valeria spends the weekend with her father, his girlfriend and her little brother. Her relationship with him has improved remarkably, but, at first, she did not usually approach him and only looked at him. As for her father's girlfriend, this is quite nice, but Valeria does not usually relate to her and does not like to see her with her father, the person on whom the girl relied the most, although currently that trusted person has become his mother, since she is the person with whom he spends the most hours. 


\section{INTERVENTION}

\subsection{GOALS}

- Learn to recognize and identify your own emotions and those of others.

- Know how to express emotions through facial features.

- Develop strategies that help us control certain emotions.

- Know how to manage emotions depending on the situation in which we find ourselves.

- Develop social skills showing empathic, supportive and constructive attitudes with other colleagues.

\subsection{SKILLS TO WORK}

- Emotional competence: Because this project revolves around emotions, this competence is essential since emotional education and the promotion of emotional intelligence is essential to work at any age and in any environment, such as at school and in the family, when same as in this project.

- Linguistic communication: this competition will be developed in the different communication exchanges between student-student, student-teacher, student-family. This oral, written and gestural communication will be essential to promote socialization through the expression of emotions.

- Social and civic:It is important to apply this competence in our project, since the students will learn some basic behaviors, based on values and attitudes, to relate to their immediate social environment and achieve their own personal well-being.

\subsection{CONTENT / S}

- Emotion concept

- Recognition of the physical gestures that accompany them.

- Classification of emotions (positive and negative)

- Self-regulation of emotions

\subsection{ACTIVITIES}

Our didactic proposal consists of an educational project, called "Feeling makes us equal", which will be developed across the classroom during the first seven days of the school year. With its implementation we intend that this be included as a curricular project of the center, since we consider that 
the content worked with it is of utmost importance in the personal development of the students. In addition, it is a topic that, in general, and despite its significance, is often forgotten by some teachers.

As we have commented previously, the project will be implemented during the first and part of the second week of the first quarter. For this, during this period approximately one hour a day will be dedicated, which will be assigned by the teachers who normally teach at that time, for the development of the project. Although more time will be spent in class during the first and second week, we will design a material with the aim that we can give continuity to the subject discussed during the course of the course. In addition to the activities planned and carried out during these seven days, we can use this content whenever there are conflictive or novel situations in which the students do not know how to act.

Therefore, to continue working with this project throughout the course, every weekend a child will take home the book called "Today I feel" (Annex 1), in it they will have to continue with the same guidelines that we will indicate in class and, with the help of their parents, they will complete the book with the different emotions they feel during those days. Afterwards, every Monday about half an hour of the first class will be dedicated for them to comment on it and learn different emotions each week.

Since we need the help of the parents, the tutor, he will make a meeting with them before they start taking the book home. In this meeting they will be given information about the different objectives and contents that are intended to be achieved with this project, and they will also participate in them so that they collaborate with their children in the proper functioning of the project, helping them to understand the emotions and the realization of the book.

\section{METHODOLOGY}

\subsection{DAY 1: PRESENTATION "AND YOU, WHO ARE YOU?"}

Our project will start at the beginning of the first term of class as soon as we enter the classroom, due to being the moment in which, possibly, more different emotions may be present in the classroom environment as a consequence of the first and different sensations that the student body can have and perceive, for example: seeing friends again, being in a different class from the previous year, meeting a new teacher, being sad for not wanting to go back to school, etc.

The first activity of this project begins as soon as the students enter the corresponding classroom for this new course. In it you will find as many helium balloons as children are in class. These balloons will be of three different colors and from each balloon will hang three envelopes connected by a thread.

First, each child will be given a sheet where they will have to write, anonymously, how they feel on their first day of school and why. Next, each child will put this page in the first envelope of a balloon. Once everyone has finished, the balloons of the different colors will be mixed. 
Second, each child will choose a balloon of a different color from the one they picked up in the previous batch. Next, they will read the page that has been inserted in the first envelope by another of their classmates and, depending on what is written, they will have to draw the expression of the face (happy, sad, surprised ...) that they think has the partner who has written it. When you finish drawing the face, you will put the sheet in the second envelope and the balloons will be mixed again.

Third, the mechanism will be repeated, first they will take a balloon of a different color from the other two occasions and then they will look at the page of the second envelope. Once they have analyzed the facial expression drawn, they will write on the last sheet that is given to them how they think the child in the drawing feels, and they will put it in the third envelope. This last step will allow us to know if they are able to recognize emotions and if they know some of their names, although they do not really know the meaning of emotion.

Next, each student keeps the third balloon and when they all finish they will be told the next task. This consists of sticking the three pages inside the envelopes on a cardboard, in the same order corresponding to the envelope in which they are found. The purpose is for each student to evaluate whether the drawing of the face (second envelope) agrees with the feeling that the partner has written (first envelope) and what has been transmitted to him / her (third envelope). They will then discuss their feelings in small groups and later in a large group. The second step will be to glue all the cards back into a larger one and it will be placed on one of the walls of the classroom.

Finally, the teacher will suddenly take out a white balloon from which only a first envelope hangs. The teacher will be in charge of creating a climate of uncertainty and interest in the classroom, using one of the following questions: why isn't it the same colors as the others? Do you know who it can be from? Who is hiding? and do not want to leave? Once they have expressed their ideas, the teacher should show them to their new partner, Tomasito (Annex 2). This will be a doll, but it is not like any doll, but a special doll-companion, since it has neither eyebrows, nor eyes, nor mouth.

A volunteer will be asked to read the inside of the first envelope of Tomasito's balloon and they will realize that there is nothing written. The students will ask themselves questions such as: "why does his envelope have a blank?", "Why doesn't he have an expression on his face?", Etc., but Tomasito will answer their questions until the next day.

\subsection{DAY 2: THE SADNESS "WHY DON'T YOU SMILE?"}

On the second day, it must be borne in mind that, if the previous session has been carried out satisfactorily, the students will return wanting to know more about Tomasito. Therefore, the teacher will ask him if they want to help him and what guidelines we must follow to do so. First, we will listen to your 
ideas by asking questions such as: "What do you do when you want to know what happens to a friend?" (1st LISTEN), "once you have listened to it, what do you think your friend would like you to do?" (2nd UNDERSTAND IT), "and then what can you do to make her feel better?" (3rd HELP). Therefore, these will be the three steps (listening, understanding and helping) that we will follow in the different activities that are proposed to work on an emotion each day of this first week of class.

\section{Hear}

When the students have been able to understand the guidelines, Tomasito will tell them what is happening to him. This day the emotion of sadness will be worked on and for this the song Movement Concert for Piano No. 5 by Beethoven will be put in the background at the same time that the teacher will present the story of Tomasito playing the role of ventriloquist.

History: "Hello, my name is Tomasito and as you will see I have no face, well, actually I do, what happens is that sometimes I find it difficult to find it. I know all this will sound strange to you, but I have to confess a secret, don't say anything, but ... my face doesn't know how to express what I feel. My mom says it's about something called emotions, I think, however, I still don't understand it, do you have any of that? This year I am new to school, I have changed because in my previous school everyone looked at me as if I were strange, nobody wanted to play with me and I had no friends, but your teachers have told me that you are special and that you can help to have a face again, although I still do not know if it is true and that makes me feel very lonely. "Do you know what face it should have at this moment? And ... what emotion does it represent?"

\section{Understand}

Next, each student is given a template with the margin of Tomasito's face and a sheet where they will have to draw the eyes, mouth and eyebrows, depending on how they think Tomasito's face should be at this time, and also write the emotion they think it is about (sadness). Then they will cut out the pieces (eyes, mouth and eyebrows) and glue them with velcro to their template. Next, each student will expose to the rest what face they have drawn for Tomasito and among all of them they will choose the one that most identifies them to put it on.

\section{To help}

This will be the last step. It consists of helping Tomasito so that he does not feel sad. In groups they will prepare a small activity (dance, song, poem...) in order to get Tomasito to see how special they are and to be able to trust them. In turn, they will present the activity to the rest of the groups, to the teacher and to Tomasito so that they can participate in it. 


\subsection{DAY 3: JOY "I HAVE A NEW FRIEND"}

This day we will begin the dynamic by playing the song "Payday" by Jason Farnham while Tomasito enters the class humming and dancing. Once our character has entered class, he will begin to tell how happy he is and what is due. As I tell the story, songs will not stop playing that transmit to the students that feeling of joy so that they can more easily spread the happiness that Tomasito gives off that day. And the story that he tells them is the following:

"Hello boys and girls. Today I woke up in a very good mood, I have a strange and at the same time very good feeling that I could not explain. The fact is that yesterday you made me feel very good, because in the other school I almost had no friends and when I got here I found that I have many. But that's not all, in the afternoon when I left home I went to the park next door and there were many children playing. I'm a bit shy, but thanks to the trust you gave me, I approached a child and we started talking. And why don't you know what? We had a lot of things in common! We liked the same music, the same toys, our favorite movies were the same, and he also told me a movie that I hadn't seen, but I sure love it. We spent the whole afternoon talking and playing, I had a great time with him. Namely,

"What do you think guys? Don't you think it's very exciting too? Why do you think I feel like this? I just couldn't explain it ..."

At the end of the story, we will enter the next phase. That is, the students will try to understand and understand the character and why they feel so happy. The children will answer Tomasito's questions and must draw in their notebook, just like the rest of the days, the expression of the character's face and give it to them.will teach. In this way, Tomasito will understand what facial expression he should show on his face. That is, the expression that we all have when we are happy.

In the last phase, the students will experience all of the above for themselves, that is, what tastes they have in common with their classmates and what they do not. To do this, they will sit in a circle in their respective chairs and several songs will be played. Those who like the song that is playing will have to get up and those who do not, will remain seated. Next, the teacher will list several sports, those who like that sport will hit the hand with the one they also like. And finally, we will list several books and movies following the same dynamic as with songs, that is, whoever likes that book or movie will get up and whoever doesn't, will remain seated.

In this way, children will understand that having things in common with a partner is a good way to become friends and that, in addition to choosing our friends, this is a very exciting / rewarding task that results in that feeling of happiness and joy. that we set as an objective in this activity. 


\subsection{DAY 4: THE FEAR “HOW DARK IT IS!"}

As in the previous activities, we will begin with the phase dedicated to listening to what happens to Tomasito. Our character will arrive, one more day, telling the students what happened the day before. The story will be accompanied by some effects that we will be introducing in order for students to enter the story more easily, which is the following:

"Hello boys and girls. Do you know what happened to me last night? We were all at home watching a super cool movie when, suddenly, it started to rain very hard (we put on the sound of a storm). So much so that, in the middle of the film, an atrocious thunder was heard and, immediately afterwards, the house light went out (we turned off the class light). From that moment, my little brother started crying non-stop (crying sound). I didn't understand why he was crying so much and why all he wanted was for my parents to hold him. In addition, my parents also seemed to be a little nervous because they ran all over the house looking for candles in all the drawers. "

Once this first phase is finished, we will go on to the next one, in which the students try to understand / understand Tomasito:

"I tell you this because I think you can help me.... What do you think happened to my brother? Why was he crying and crying non-stop? "

Once the questions posed by the character have been answered, the boys and girls will draw, as in the previous days, the facial gestures necessary to express their fear and then they will stick them with velcro to their template. In this way, they will show Tomasito, the facial expression that is usually used when someone feels this emotion.

Finally, in phase number three, in which we try to help Tomasito, first of all, we will propose some relaxation techniques that we can use when we are afraid and nervous. A very useful resource will be "the bottle of the senses", which will be made by the students themselves. To do this, the day before, students will be asked to bring the necessary materials to class (small plastic bottle, food coloring, glitter and corn syrup), and we will go on to make them.

This will be a very valuable resource, as each of the students will have their bottle at their fingertips, which will be used whenever they are nervous. By manipulating it and observing what happens inside the bottle, they stop thinking about what worries them and their pulsations decrease, until they reach a state of calm. 


\subsection{DAY 5: EL ASCO "PUAG..."}

On the fifth day we will begin the activity with the song Prelude op. $28 \mathrm{n}^{\circ} 18$ by Frederic Chopin and like every day, Tomasito will enter class, this time accompanied by a mysterious box that he will leave on the table and begin to tell his story:

"Good morning boys and girls, something very strange happened to me yesterday. I was playing in the kitchen when I touched the food that my mom was making, I felt a chill inside, I quickly pushed my hand away, it was an anguished and disgusting feeling. My stomach churned and I had to calm down to make it go away, it was a very bad feeling. My mother told me that I shouldn't feel that, since it was food, that although the touch might be strange for me, I should always respect food and eat it to make myself very big. "

"What do you guys think? What do you think I felt? Has something like this ever happened to you? $"$

After the story, Tomasito will show them the mysterious box that he carried with him but without showing them its interior. The students one by one will put their hand inside and smell without being able to see what it hides. After this, Tomasito will show them what the box contains (a sticky dough made with a mixture of flour, water and food coloring).

The students will go on to the next phase; in which they will understand and understand the story trying to find out the emotion that Tomasito feels and the reason for the anguish he has felt.

The children will answer the questions that Tomasito will ask and as each day they will have to draw in their notebook the expression on the face that reflects the corresponding feeling, after this they will show it to Tomasito so that he understands what facial expression he should show.

Finally, in the last phase, Tomasito will bring the ingredients with which he has made the mixture and the students will be able to make their own. With it each one will make a figure that does not convey the feeling of disgust. This figure will be put into the oven and shown to the students. In this way, what initially disgusted them will finally become a fun figure made by them. That is, they will learn to control it.

\subsection{DAY 6: THE ANGER "WHY ME?"}

In this session Tomasito enters class very excited and nervous. This is followed by the song Fantasy and Fugue on the name of Bach by Franz Liszt and immediately afterwards, he begins to tell his story:

"Boys and girls, today my heart beats very fast and a very strange energy runs through my body. It turns out that yesterday I went to my friend's house on a bicycle, the one I told you about the other day. 
When I arrived I left it tied with the chain to a post that was right in front of the door of my friend's house. We were playing and having a good time all afternoon, but when I got out my bike was gone. Can you believe it? " "Has something like this ever happened to you?" "How would you feel if it happened to you?"

Then, a little time will be left for the students to tell their own experiences, and how they felt. Afterwards, the boys and girls will draw the features in Tomasito's facial expression that represent anger and attach them to their template with Velcro. Likewise, they will teach Tomasito, once again, what is the facial expression that is usually used for this emotion.

Finally, in phase three, the teacher will place a large piece of continuous paper on the floor and provide the students with finger paintings of different colors. To carry out the activity, the students will sit around the paper and will have to think of a situation that makes them feel very angry. Then they will draw and paint, freely and with their hands, something nice, lines, some words, etc. in order to vent and forget about anger through painting.

\subsection{DAY 7: SURPRISE "WHAT IS THIS?"}

This is the last day that we will work on Tomasito's primary emotions. The doll enters class with a satisfied look, but at the same time it seems that he is pensive. The song that will sound will be Umore Ona by Fito y Fitipaldis.

The students will wonder what happened to Tomasito and he will tell them the following story: "Yesterday, when I got home my mother was waiting for me more eager than ever, she kept talking very fast and telling me to give me a lot. rush. I didn't understand anything, but he didn't want to explain it to me either, he just told me that we had to go down to the garage for a moment. When I opened the door it was all dark and immediately the lights came on and with them a cry of surprise! All my family and friends were there, they had prepared a party for my birthday! I didn't know what to say or what to do, but I ate a lot of cake and received many gifts. My mom kept asking me if I had liked it, how could I not like it? Besides her, many people also told me. Could it be because I couldn't really express what I was feeling? And if so, do you know how to do it?"

When they talk with Tomasito, they will go on to make the drawings of the expression of surprise on his template to help him express this emotion in other possible birthday parties, or situations that may require it.

Finally, in the last phase, we will perform in class and in pairs, the representation of different surprise situations, in which the students will have to express facially and gesturally what they would do at all times. For example:

1. Finding a friend in the park that you haven't seen in a long time. 
2. Receive a gift that you wanted very much.

3. When your grandparents who live in another city visit you.

\subsection{MATERIALS}

- Character "Tomasito", who will become the common thread of the project.

- Traveling book of emotions, which will be the resource that they will continue to use throughout the school year to continue developing this content.

- Prints "Today I feel"

- Calm bottle

\subsection{EVALUATION:}

Evaluation is an essential part of the teaching-learning process because, through it, teachers obtain very valuable information about the process, the methodology and about our students. In this way, if this is carried out properly, we will not have to wait until the end of the project to introduce the necessary modifications, since the evaluation must be a process that is carried out continuously and from the beginning of the project. In addition, in our case, as it is a cross-cutting project that will continue to be developed throughout the course, the evaluation will be much more enriching, since we will be able to observe the evolution of our students.

The results of the students will be reflected through various evaluation processes. First, the book of emotions "Today I feel" that each student takes home for two or three days, will be a way of evaluating whether the boys and girls identify Emotions correctly, express them in an appropriate way, through the facial expression represented in the photo that must be made and, finally, if they are able to detect other emotions different from those discussed in class.

On the other hand, a rubric (annex 3) will also be carried out where we reflect the learning and deficiencies of each student at the end of each activity or session, a questionnaire (annex 4) for their parents in The one who will answer how this project has helped their children, observing them both on the days in which it corresponds to take the book to their children and in their day to day life and, finally, various meetings with family members before, during and after the teaching-learning process to collect information about the child's socio-affective context and explain to them what is going to be addressed in the project, how it is going to be carried out and what purpose is sought with it. 


\section{GENERAL CONCLUSIONS}

In carrying out this project we have immersed ourselves in a world that is a bit unknown to us, since we had never before addressed emotions in depth nor had we considered the possibility that this was a content that could be taught in school. However, now we understand the importance of addressing it and we do not see that it can be taught, but we believe that both expressing and controlling all the feelings and emotions that run through us must be taught. As in all the works, in the elaboration of this, we had both positive aspects and others that we should improve, which leads to some difficulties to which we have exposed ourselves.

In the first place, we have realized that activities can be proposed that include the whole class, without excluding anyone and that transmit the same feelings in all children. We have been able to educate feelings in a playful and practical way, because when dealing with feelings and emotions it was necessary for children to put themselves in the shoes of both Tomasito and themselves in various situations and know everything in this way. what is happening to them at all times. In addition, with this work and the exhibitions, we have been able to observe the various ways in which the treatment of emotions can be carried out through the work carried out by our colleagues, learning about other diseases and the different ways of thinking they have to be given depending on them.

In another aspect, we have encountered various difficulties such as thinking like a boy or girl with Autism Spectrum Disorder, because throughout our lives we have normalized the expression of emotions. However, we do not think of those who find it more difficult to identify these aspects, much less put them into practice. It has also been difficult for us to find a common thread for the entire project that would give us continuity and allow us to follow the three phases that we have addressed in each activity in each of the sessions, until we finally found Tomasito.

Finally, as regards the aspects to be improved, we would highlight the dynamics carried out in the exhibition, because when we stuck the balloons on the wall we did not take into account the number of colleagues who would attend, and when putting the papers in the envelopes we did not They knew which ones were used and which ones were not, as well as not having followed an order for them to choose the balloons, open the envelopes and carry out the task. 


\section{ANNEXES}

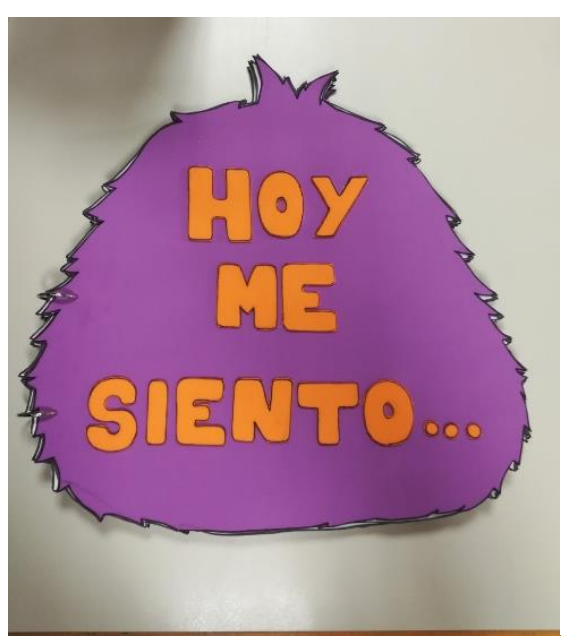

Appendix 1:

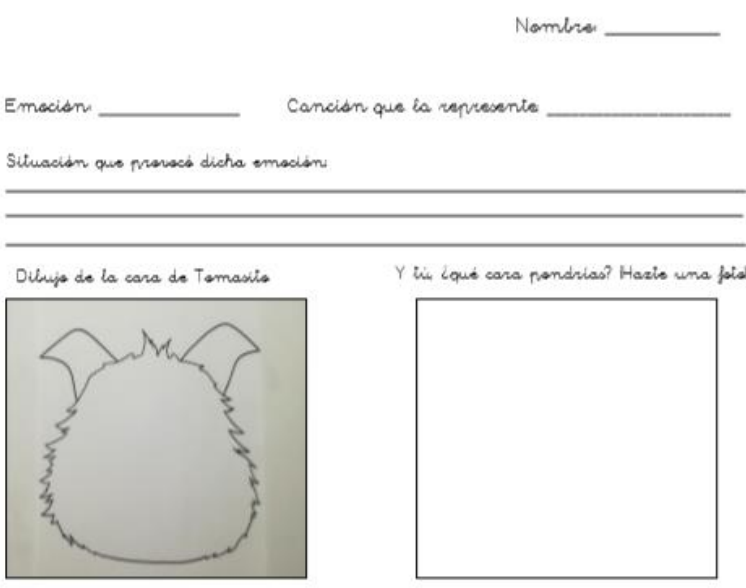

Appendix 2:

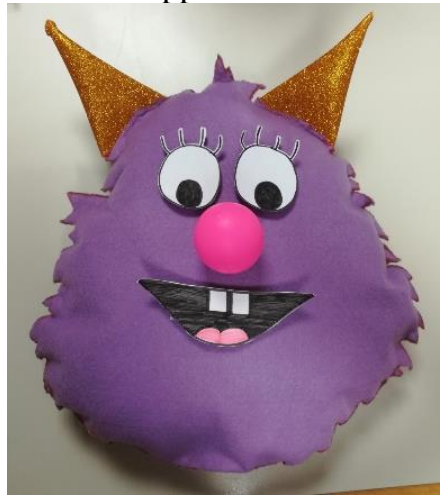

Annex 3:

ASPECT TO EVALUATE: Emotions: their expression and control.

4. Presents the ability to control their emotions when the situation requires it. 3. The student presents a correct exposition of his emotions without harming himself or others. 2. You have not developed a complete ability to express your feelings. 1. Emotional overexcitement: you do not control or express your emotions adequately.

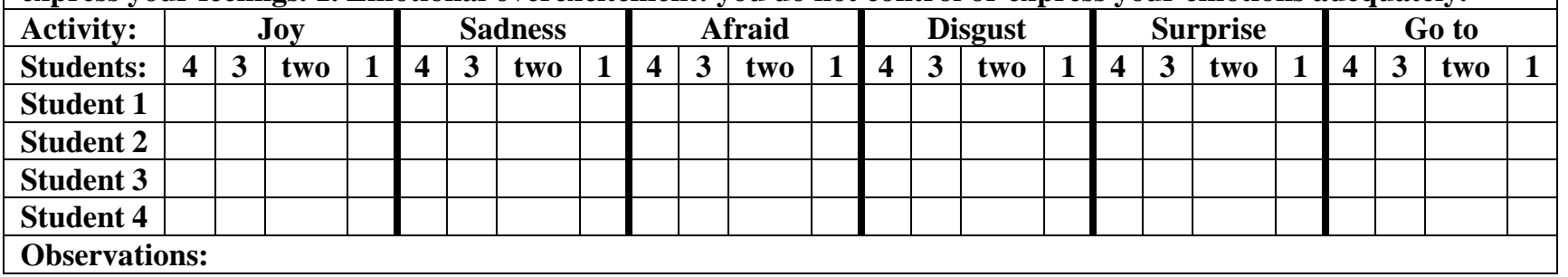

Annex 4:

\section{QUESTIONNAIRE FOR MOTHERS AND PARENTS}

1. Was your child enthusiastic about completing his page in the book "Today I Feel..."?

a) He commented on it at home before bringing it in and was really looking forward to it.

b) Once he brought it home he explained to us what it was about. 
c) We were the ones who insisted that he show it to us.

\section{How was the process of choosing an emotion and reflecting it?}

a) From the first moment it was clear what the emotion was going to be.

b) He had some ideas in mind and we helped him choose one.

c) We were the ones who offered to help him from the first moment because he did not know what emotion to do.

\section{Was it easy to find the situation that reflected that emotion?}
a) He knew perfectly the different situations that could be related to the emotion.
b) He had some idea about the situation, but we had to help him figure it out.
c) He did not know how to relate the situation to emotion.

\section{The taking of the photo ...}

a) It was easy to take the photo because from the first moment he knew what face to put on.

b) We made several photo attempts but in the end he succeeded.

c) Despite numerous photos and attempts at imitation, we did not succeed. 


\section{BIBLIOGRAPHIC REFERENCES}

Barratt, P., Clewley,H., Joy, H., Thomas, G. (2004). El Síndrome de Asperger--Estrategias Practicas para el Aula: Guia para el Profesorado. Recuperado de http://www.xtec.cat/ mjulia/alumnat/avalua/guiaAsperger.pdf

Belinchón, M., Hernández, J.M. y Sotillo, M. (2009). Síndrome de Asperger: Una guía para los profesionales de la educación. Recuperado de https://www.asperger.es/sindrome_infancia_sintomas.html Cobo, M.C. y Morán, E. (2011). El Síndrome de Asperger. Intervenciones psicoeducativas. Recuperado de http://sid.usal.es/libros/discapacidad/26529/8-4-1/el-sindrome-de-asperger-intervencionespsicoeducativas.aspx

Darretxe, L. y Sepúlveda, L. (2011). Estrategias educativas para orientar las necesidades educativas de los estudiantes con Síndrome de Asperger en aulas ordinarias. Electronic Journal of Research in Educational Psychology, 9(2), pp.1-24. Recuperado de http://www.redalyc.org/articulo.oa?id=293122840018 